\title{
Advanced maternal age: Are decisions about the timing of child-bearing a failure to understand the risks?
}

\author{
Karen M. Benzies RN PhD
}

$\infty \quad$ See related article page $\mathbf{1}_{5}$

$\mathrm{I}$ $\mathrm{n}$ the developed world, an increasing proportion of births are attributable to women of advanced maternal age ( $\geq 35$ years). ${ }^{1,2}$ Between 1995 and 2003, the mean age of first-time mothers in Canada increased from 28.8 to 29.6 years. ${ }^{3}$ On average, first-time mothers in Canada are older than first-time mothers in other developed countries, including Sweden (mean age 28.3 years), the Netherlands (28.7 years) and the United States (24.9 years). ${ }^{4}$ Traditionally, women have been the subject of reproductive interventions and policies. However, the trend toward delayed parenthood and risks associated with advanced age also apply to men. ${ }^{5,6}$ These changing patterns of advanced age of first-time parents are having a significant public health impact owing to increased risks of stillbirth, preterm birth and cesarean delivery. ${ }^{7}$ Reducing adverse perinatal outcomes requires comprehensive and systematic examination of the complex relations among factors that contribute to decisions about the timing of child-bearing.

In this issue of CMAJ, Huang and colleagues ${ }^{8}$ report the results of a systematic review of retrospective cohort and case-control studies of the association between advanced maternal age and the risk of stillbirth. Although first-time mothers in Canada are older than those in other developed countries, ${ }^{4}$ the rate of stillbirth -3 per 1000 total births - is similar to that in Sweden (3 per 1000), the Netherlands (5 per 1000) and the United States (4 per 1000). ${ }^{9}$ Huang and colleagues ${ }^{8}$ are to be commended for the breadth of their review, which included 37 studies from 4 continents reported in 5 languages. Although clinical, methodological and statistical heterogeneity prevented meta-analysis, Huang and colleagues ${ }^{8}$ found that $77 \%$ of the 3I retrospective cohort studies and all 6 of the casecontrol studies indicated a statistically significant association between advanced maternal age and stillbirth risk. They found a similar association in all I5 population-based cohort studies. They concluded that advanced maternal age likely has an independent effect on stillbirth.

One of the most serious challenges in conducting reviews in this area is the variability in definitions of advanced maternal age and the threshold for reporting stillbirth. ${ }^{10}$ At a minimum, consensus about definitions and standardized reporting across jurisdictions would lead to more definitive results from systematic reviews. Additional study variability arises from differences in health care and cultural contexts, which are not sufficiently captured in epidemiologic or hospitalbased administrative data sets. This limits the ability to generalize findings to other populations. However, as Huang and

\section{Key points of the article \\ - On average, first-time mothers in Canada are older than women in other developed countries. \\ - Canadian men and women do not fully understand the link between advanced maternal age and adverse outcomes, such as stillbirth. \\ - By providing information to all patients of child-bearing age about the medical risks of advanced maternal age, phys- icians will contribute to more informed decisions about the timing of child-bearing.}

colleagues $^{8}$ correctly point out, there remains a great deal to learn about the impact of lifestyle and socioeconomic factors on stillbirth risk. Although large, prospective studies that include information about prepregnancy health of the mother and father, maternal stress and socioeconomic factors are expensive, a clear understanding of the risk of stillbirth will require this level of investment in research.

The results of the review by Huang and colleagues ${ }^{8}$ are somewhat consistent with those of the study by Fretts ${ }^{10}$ who identified that, in addition to advanced maternal age, prepregnancy obesity and socioeconomic factors were the most prevalent risk factors related to the 709 Canadian stillbirths recorded in the McGill Obstetrical Neonatal database. Similarly, in a population-based Italian sample, the risk of adverse pregnancy outcomes associated with advanced maternal age was modified by parity and education. ${ }^{1}$ After adjusting for a large number of known predisposing conditions in a population-based US cohort, Bateman and Simpson ${ }^{11}$ identified an independent risk of maternal age, with higher rates of stillbirth at both extremes of reproductive age ( $\leq$ I9 and $\geq 35$ years). Although maternal age contributes to the risk of stillbirth in developed countries, infection, malnutrition, lack of antenatal care and poverty constitute the major risk factors in developing countries. ${ }^{12}$

The major causes of stillbirth vary by gestational age. Infection is the most common contributor between 24 and 27 weeks' gestation, and unexplained stillbirth is the most common contributor after 28 weeks. ${ }^{10}$ In the study by Fretts, ${ }^{10}$ rates of unexplained late fetal loss were more pronounced among women aged 35 years or older. This rate is similar to

Karen Benzies is with the Faculty of Nursing, University of Calgary, Calgary, Alta. 
that reported among women aged 45 years and older in a population-based Swedish study. ${ }^{13}$ Together, these studies clearly suggest a multifactorial cause of stillbirth and a clear need for prospective studies that include lifestyle and socioeconomic risk factors.

Much remains to be learned about why women and men delay child-bearing and about their knowledge of the associated risks. Women's decisions about the timing of childbearing are influenced by many factors. In a qualitative study involving women aged $20-48$ years, independence, motivation to have a family, declining fertility, chronic health problems and stable relationships were identified as personal influences on decisions about the timing of child-bearing. ${ }^{14}$ Family influences included partner readiness for childbearing, financial stability and the influence of extended family. ${ }^{14}$ Societal influences included increasing acceptability of advanced maternal age, divorce rates and parental-leave policies in the workplace. ${ }^{13}$ In one of the only studies to explore why men decided to delay having children, influencing factors were similar to those influencing women's decisions and included financial security, partner suitability to parenting and motivation to have children. ${ }^{15}$ Although this and another population-based study have suggested that men and women are aware of the relation between advanced maternal age and conception difficulties, the studies found that they are generally unaware of other medical risks, including stillbirth, cesarean delivery, multiple births and preterm delivery. ${ }^{15,16}$ Prepregnancy counselling for patients who delay childbearing into their late zos may be too late to inform decisions about preventing pregnancy risks associated with advanced maternal and paternal age. A survey of Canadian obstetricians, gynecologists and family physicians reported many missed opportunities to identify women who are at risk for adverse conception, pregnancy and birth outcomes. ${ }^{17} \mathrm{Al}-$ though physicians have incorporated discussions of birth control and Papanicolaou smears into their routine care of women,${ }^{17}$ screening and providing information about fecundity, nutrition, weight management, alcohol, smoking, mental illness, addictions and stress may increase the chances of optimal reproductive outcomes. Currently, it appears that decisions about the timing of child-bearing are not based on an informed understanding of the risks associated with suboptimal reproductive outcomes..$^{15}$ Although information alone is insufficient to change behaviours, it may contribute to more informed decisions about the timing of child-bearing.

Finally, an interactive model to assess the risk of stillbirth is needed to guide pregnancy management. Large, prospective studies that include lifestyle and socioeconomic factors are also needed. Given the increasing birth rate among women of advanced maternal age and the resource con- straints facing the health care system, increased fetal testing based on advanced maternal age alone may be unfeasible. Prevention of stillbirth may require a broader assessment of risk factors and additional attention to prepregnancy counselling and testing for women and men. Huang and colleagues are to be commended for expanding the awareness of advanced maternal age as one of the risk factors for stillbirth.

This article has been peer reviewed.

Competing interests: None declared.

Acknowledgement: I thank Dr. Suzanne Tough, Department of Pediatrics, University of Calgary, for reviewing and providing feedback on this commentary.

\section{REFERENCES}

I. Astolfi P, Zonta L. Delayed maternity and risk at delivery. Paediatr Perinat Epidemiol 2002; I6:67-72.

2. Tough SC, Newburn-Cook C, Johnston DW, et al. Delayed childbearing and its impact on population rate changes in lower birth weight, multiple birth, and preterm delivery. Pediatrics 2002;109:399-403.

3. Reproductive Health Working Group. Alberta reproductive health: pregnancies and births 2006; 2006. Available: www.health.gov.ab.ca/resources/publications /reproductiveo6.pdf (accessed 2007 Dec 7).

4. United Nations Economic Commission for Europe. Trends in Europe and North America: the statistical yearbook of the Economic Commission for Europe 2005 Geneva: The Commission; 2005. Available: www.unece.org/stats/trends2005 |Sources/II5_B_Mean\%20age\%200f\%2owomen\%20at\%2othe\%2obirth\%200f\%2 othe\%2ofirst \%2ochild.pdf (accessed 2007 Nov 22).

5. Bray I, Gunnell D, Davey Smith G. Advanced paternal age: How old is too old? J Epidemiol Community Health 2006;60:85I-3.

6. De La Rochebrochard E, de Mouzon J, Thepot F, et al; French National IVF Registry association. Fathers over 40 and increased failure to conceive: the lessons of in vitro fertilization in France. Fertil Steril 2006;85:I420-4.

7. Joseph KS, Allen AC, Dodds L, et al. The perinatal effects of delayed childbearing. Obstet Gynecol 2005;105:I4IO-8.

8. Huang L, Sauve R, Birkett N, et al. Maternal age and risk of stillbirth: a systematic review. CMAJ 2008;178:165-72.

9. World Health Organization. The world health report 2005. Geneva: The Organization; 2005. Available: www.who.int/whr/2005/annexes-en.pdf (accessed 2007 Nov 28).

Io. Fretts RC. Etiology and prevention of stillbirth. Am JObstet Gynecol 2005;I93:1923-35

II. Bateman BT, Simpson LL. Higher rate of stillbirth at the extremes of reproductive age: a large nationwide sample of deliveries in the United States. Am J Obstet Gynecol 2006; I94:840-5.

I2. Di Mario S, Say L, Lincetto O. Risk factors for stillbirth in developing countries: a systematic review of the literature. Sex Transm Dis 2007;34:SII-2I.

13. Jacobsson B, Ladfors L, Milsom I. Advanced maternal age and adverse perinatal outcome. Obstet Gynecol 2004;104:727-33.

I4. Benzies KM, Tough S, Tofflemire K, et al. Factors influencing women's decisions about timing of motherhood. J Obstet Gynecol Neonatal Nurs 2006;35:625-33.

I5. Tough S, Benzies K, Fraser-Lee N, et al. Factors influencing childbearing decisions and knowledge of perinatal risks among Canadian men and women. Matern Child

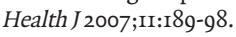

I6. Tough S, Benzies K, Newburn-Cook C, et al. What do women know about the risks of delayed childbearing? Can J Public Health 2006;97:330-4.

I7. Tough S, Clarke M, Hicks M, et al. Pre-conception practices among family phys icians and obstetrician-gynaecologists: results from a national survey. J Obstet $G y^{-}$ naecol Can 2006;28:780-8.

Correspondence to: Dr. Karen M. Benzies, Faculty of Nursing, University of Calgary; 2500 University Dr. NW, Calgary $A B$ T2N IN4; fax 403 2I0-8Ior; benzies@ucalgary.ca 